\title{
Espaços sagrados na Palestina romana: arqueologia, imperialismo e a multiplicidade ritual no Oriente Médio
}

Marcio Teixeira Bastos*

Ovadiah, Asher; turnheim, Yehudit. Roman Temples, Shrines and Temene in Israel. Roma: Giorgio Bretschneider Editore, 2011. 155 páginas e 78 pranchas.

Asher Ovadiah e Yehudit Turnheim oferecem um trabalho pioneiro de pesquisa que contribui amplamente para o estudo da arquitetura e da cultura material associada aos lugares de culto em Israel; assim como para a investigação das distintas manifestaçóes daquilo que foi considerado sagrado no período romano e a ocupação das múltiplas topografias na região. Este é o primeiro livro a tratar da arquitetura dos templos erigidos em Israel e da cultura material associada a ocupação dos templos, santuários e témenos no período romano (em seu contexto maior, a parte sul da extensa Província da Síria Romana e suas consequentes transformaçōes). O estado de conservação dos sítios arqueológicos, o número limitado de escavaçóes e a escassez de publicações sobre templos romanos escavados nessa parte do império são obstáculos que limitam a imagem e abrangência do esforço de abordagem feito pelos dois arqueólogos da Universidade de Tel Aviv na tentativa de reconstrução de práticas e lugares de culto em Israel durante esse período. A faixa cronológica dos templos, santuários e témenos discutidos neste livro se estende ao longo de um período que compreende desde o reinado de Herodes até o início da dinastia Dioleciana (primeiro século AEC até terceiro século EC).

Os autores decidiram não separar a discussão entre santuários e templos, e em alguns casos eles são apresentados conjuntamente. Um olhar apurado sobre a lista apresentada na obra mostra claramente quão variado e diferentes entre si são estes complexos. O livro é dividido em duas partes distintas: na primeira, são abordados onze sítios arqueológicos e seus respectivos santuários e templos; na segunda parte, é apresentada uma discussão de treze outros lugares, baseada essencialmente em fontes históricas, literárias, epigráficas e numismáticas, mais do que em vestígios das edificações nos sítios arqueológicos na região. Convém salientar que alguns dos sítios abordados nunca foram escavados, como é o caso da Caverna de Elijah, no Monte Carmelo; e outros sítios ar-

DOI - http://dx.doi.org/10.1590/2237-101X0173220

* Doutorando cotutela em Arqueologia do Museu de Arqueologia e Etnologia da Universidade de São Paulo (MAE-USP), São Paulo, SP, Brasil e da Universidade de Tel Aviv (TAU), Israel, com período de pesquisa na Universidade de Durham, Reino Unido (2013-2014 — bolsa Bepe-Fapesp). Bolsista Fapesp. E-mail: marcio_ quisleu@yahoo.com.br. 
queológicos escavados não têm até hoje seus resultados completos de escavaçáo publicados. Esse é o caso do santuário de Paneas (Banias), e dos três templos localizados em Citópolis (Beth Shean), que foram escavados há mais de dez anos e ainda aguardam a publicação completa e resultados finais dos trabalhos executados.

Nesse mesmo sentido, os autores apresentaram crítica ao trabalho desenvolvido pela Universidade de Minnesota no templo de Omrit, na Alta Galileia, salientando que até aquele momento nenhum resultado havia sido publicado sobre o sítio. Contudo, durante o mesmo ano de edição do livro aqui resenhado, Andrew Overman e Daniel Schowalter publicaram os resultados preliminares das escavaçóes no templo de Omrit (J. Andrew Overman e Daniel N. Schowalter, The Roman Temple Complex at Horvat Omrit: An interim report, BAR International Series 2205). A crítica de Ovadiah e Turnheim não ficou sem resposta. Dois anos depois, Andrew Overman em resenha para o Journal of Roman Archaeology (2013, vl. 26, p. 877-878) procurou rebater as assertivas analisando o livro dos autores. Por sua vez, Arthur Segal, da Universidade de Haifa, em resenha publicada em 2011 (Roman Temples, Shrines and Temene in Israel, Israel Exploration Journal, v. 61, n. 2, p. 242-246) já havia alertado para a dificuldade que os autores enfrentaram na tentativa de proporcionar uma imagem balanceada do que foi denominado como "Arquitetura do Culto Romano em Israel”. Apesar de tais críticas, é preciso salientar que, em função do quadro variado e obstáculos de acesso à informação,
Ovadiah e Turnheim chegaram à conclusão de que náo é aconselhável, para o momento, estabelecer uma tipologia de construção para as edificaçôes dos templos e santuários romanos em Israel.

$\mathrm{Na}$ primeira parte do livro (que corresponde a onze sítios arqueológicos) são abordados: 1 - Paneas-Banias / Cesareia Philippi; 2 - Horvat Omrit; 3 - Templo de Baal Shamin, em Kedesh; 4 - Beth Shean / Citópolis; 5 - Caverna de Elijah, Monte Carmelo; 6 Dor; 7 - Cesareia Marítima; 8 - Samaria-Sebaste; 9 - Templo de Zeus Hypsistos, Monte Gerizim; 10 - Jerusalem / Aelia Capitolina; 11 - Témenos de Elonei Manre e Me’arat Hamachpelah / Tumba dos Patriarcas, em Hebrom. Já na segunda parte os treze lugares que compõem a obra são apresentados sob o título "Varia". São eles: Keren Naphtali / Khirbet Harrawi; Bethsaida; Hippos / Sussita; Tiberíades; Beset; Acre (Akko) / Ptolemais; Antipátrida (Aphek) / Antipatris; Jaffa / Jope; Beth Guvrin / Eleutheropolis; Ascalon / Askelon; Gaza; e Elusa / Halutza. O Epílogo finaliza o livro e um apêndice sobre as fontes literárias, bem como a reprodução das fotos dos sítios arqueológicos, são providos no final da obra.

Os templos e santuários dedicados a Pan e outros deuses, situado no sopé da caverna de Paneas em Banias, na Alta Galileia, é um local que formou, na Antiguidade, um fascinante complexo religioso. Porém, como referido, poucos resultados das escavaçôes foram publicados em mais de dez anos após o fim das atividades. Nesse sentido, merece destaque o estudo da cerâmica ritual encontrada no sítio. O estudo feito por Andrea Berlin, 
da Universidade do Minnesota, em The Archaeology of Ritual: The Sanctuary of Pan at Banias/Caesarea Philippi apresenta excelente descrição das possíveis atividades realizadas no local. Nesse contexto de escassez de publicaçôes, a descrição do sítio apresentada por Ovadiah e Tunheim é uma fonte essencial para compreender o espaço, uma vez que tem por base, principalmente, os relatórios preliminares de escavação, além da obra de Zvi Uri Ma'oz, Baniyas in the Graeco-Roman Period: A History Based on the Excavations. No livro é possível encontrar uma análise das fontes escritas, epigráficas e numismáticas relacionadas com o sítio. Os autores procuraram utilizar toda a informação disponível, a fim de proporcionar, na medida do possível, uma imagem objetiva dos templos e santuários descritos nessa obra.

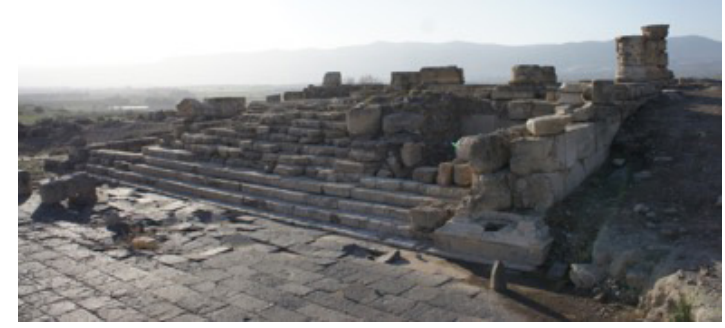

Figura 1. Santuário de Omrit, Alta Galileia (Foto: Marcio Teixeira Bastos)

No santuário de Omrit, que ainda passa por escavaçôes realizadas pela equipe da Universidade de Minnesota (Macalester College), foram descobertos três templos romanos. $\mathrm{O}$ templo mais antigo foi erguido no primeiro século AEC, talvez nos tempos de Herodes. O segundo, que teve um plano tetrastilo pe- ríptero, foi construído no final do primeiro século $\mathrm{AEC}$ ou início do primeiro século $\mathrm{EC}$, enquanto o terceiro templo, com um plano hexastilo períptero, seria uma expansão de seu antecessor e teria sido construído no decorrer do segundo século EC. Mesmo que a escavação ainda esteja em curso, não há dúvidas de que este sítio é um dos mais impressionantes templos romanos encontrados em Israel. A respeito de Horvat Omrit, os autores inferem que possivelmente o sítio serviu como um claro referencial paisagístico, assim como para propósitos eróticos e orgásticos de culto. Contudo, nada em Omrit parece sustentar essa especulação e mais evidências são necessárias para tal inferência.

As escavações no magnífico templo de Hippos/Sussita e algumas recentes publicaçóes têm consideravelmente impactado o modo como tem sido entendido e abordado o leste do mar da Galileia e as cidades da Decápolis, brevemente abordadas pelos autores no livro. Arthur Segal e uma equipe de pesquisa da Universidade de Haifa têm publicado consistentemente sobre o tema nos últimos anos (SEGAL, Arthur et al. HipposSussita of the Decapolis. The first twelve seasons of excavations 2000-2011. v. I, Haifa: The Zinman Institute of Archaeology, University of Haifa, 2013 ).

Ainda na primeira parte do livro, uma detalhada descrição do Templo de Baal Shamin em Kedesh (escavado por Ovadiah, Fischer e Roll em 1984) é apresentada. Sem dúvida um trabalho de fôlego sobre um templo romano preservado em estado satisfatório (os resultados das escavação desse sítio foram publicados amplamente). A respeito da ca- 
verna no Monte Carmelo, o questionamento de Overman sobre a estrutura ali existente é válido: trata-se de templo, santuário ou témenos? Provavelmente nenhuma dessas opçóes, como Ovadiah e Turnheim afirmam, tendo em vista que náo existe evidência da ocupação da caverna em período romano. Assim, as duas páginas sobre esse sítio dependem em maior medida de algumas fontes literárias, notadamente Tácito (Hist. 2.78), que também afirma não haver um templo no lugar, mas considera que a "tradição da Antiguidade" reconhecia no local a presença de um altar e associação sagrada.

Assim, conforme salienta Mircea Eliade em $O$ sagrado e o profano: a essência das religiōes, dentro das práticas de consagração dos espaços, a valorização e a desvalorização de locais sagrados organiza uma hierarquização dos lugares e dos territórios. Isto contribui para o fortalecimento e/ou enfraquecimento do referencial de territórios ocupados na composição dos espaços. A seleção e consagração dos lugares depende em maior medida da capacidade que uma dada modalidade do sagrado tem de criar tipos de associação e uma rede de memórias atreladas à irrupção do sagrado naquele determinado contexto. As edificaçóes sagradas e, portanto, os lugares em que elas se encontram, contribuem para a inteligibilidade associativa do que é considerado sacro e do que é considerado profano.

Entre os capítulos VII e VIII, Ovadiah e Turnheim descrevem dois templos erigidos sob a patronagem de Herodes durante o primeiro século AEC em honra e culto ao imperador Augusto. Estes são o Augus- teum de Cesareia Marítima e o Augusteum de Samaria-Sebaste. Contudo, as publicações sobre Cesareia Marítima são mais consistentes para os estudiosos que procuram aprofundar o entendimento a respeito do sítio (ver HOLUM, Kenneth et al. Caesarea reports and studies: excavations 1995-2007. Oxford: Archaeopress, 2008 e PATRICH, Joseph. Studies in the archaeology and history of Caesarea Maritima. Leiden; Boston: Brill, 2011). Apesar dos poucos itens de decoração arquitetônica desenterrados e dos comprometidos segmentos das paredes das fundações do templo, o esforço de pesquisa dos autores proporciona uma imagem crível do santuário, construído sobre uma plataforma artificial na costa do Mediterrâneo, a alguns metros do porto da cidade (nominado de Sebastos). Melhor preservado estava o Augusteum em Samaria-Sebaste, localizado no ponto mais alto da cidade, como parte de outro magnífico santuário. Embora escavado na primeira metade do século XX por equipes norte-americanas e britânicas, as pesquisas estão ainda em desacordo a respeito dos estágios de construção e do plano do templo (REISNER, George Andrew; FISHER, Clarence Stanley; LYON, David Gordon. Harvard Excavations at Samaria, 1980-1910. Cambridge: Harvard University Press, 1924, 2v.; CROWFOOT, John Winter; KENYON, Kathleen Mary; SUKENIK, Eleazar Lipa. The Buildings at Samaria I. London, Palestine Exploration Fund, 1942; Netzer, E. The Augusteum at Samaria-Sebaste: A New Outlook. Eretz-Israel, v. 19, 1987, p. 97-105). O livro de Ovadiah e Turnheim oferece aqui um ex- 
celente material comparativo e elucidativo para compreender a questáo.

Pouco restou do templo de Zeus Hypsistos, escavado em Tell er-Ras em Monte Gerizim. Entretanto, a escavação e a riqueza de informaçóes numismáticas e das fontes históricas permitiram uma reconstrução dos planos do santuário e do templo (MAGEN, Yitzhak. Mount Gerizim; MAGEN, Yitzhak. Flavia-Neapolis, Shekhem in the Roman Period. Jerusalém: Israel Exploration Society, 2005). O templo teria um plano tetrastilo períptero, com o santuário retangular construído em dois níveis. Esse templo contava com uma via de procissão (a via sacra) que consistia basicamente em uma longa escada sobre a íngreme encosta da montanha conduzindo diretamente ao santuário no topo do monte. A via sacra ramificava-se a partir da principal via colunata da cidade. No que diz respeito aos quatro templos erigidos em Jerusalém, após ser refundada e renomeada como Élia Capitolina (Aelia Capitolina) em $130 \mathrm{EC}$, estes lugares foram dedicados às divindades de Zeus/Júpiter, Aphrodite/Venus, Asclepius/Serapis e Tyche/Fortuna, respectivamente. A informação sobre estes templos deriva essencialmente de fontes históricas, literárias e numismáticas, uma vez que pouquíssimos vestígios arqueológicos restaram destas edificaçôes, em grande medida devido ao processo de cristianização da Palestina a partir do quarto século EC. Nesse sentido, assim como a Caverna de Elijah, no Monte Carmelo, seria mais apropriado alocar estes lugares na segunda parte do livro.

A primeira parte do livro encerra-se com a discussão dos dois témenos encontrados nas imediaçóes de Hebron: o témenos de Elonei Mamre e o de Me'arat Hamachpelah (Tumba dos Patriarcas). As edificaçóes foram construídas no final do primeiro século EC, ao que parece no mesmo período em que foram construídos o Augusteum de Cesareia Marítima (e também o de Samaria-Sebaste). Porém, não existe uma relaçáo objetiva entre estas edificaçôes. Os témenos claramente possuem inspiração Oriental e consistem em duas praças retangulares abertas, formada por paredes com sólidos blocos de rocha. Nestes espaços reuniam-se os participantes das cerimônias comunais e ritualísticas. Novamente se torna pertinente a pergunta: como podemos diferenciar estas estruturas? Basicamente, a origem de témenos está associada à escrita micênica Linear B e seu conceito surge associado a um terreno delimitado e consagrado a um deus, portanto, excluído dos usos seculares. O conceito também pode aplicar-se ao topos do bosque sagrado, ou, de modo genérico, à sacralização de uma dada paisagem (Carl Jung em Psicologia y alquimia associa o termo ao conceito do circulo mágico, que atua como um espécie de "lugar seguro", onde se pode "trabalhar" mentalmente). Contudo, o sentido atribuído a témenos pelos autores está ligado a uma porção de terra em um domínio oficial, especialmente separada para um basileo (soberano) ou anax (rei supremo). Cabe dizer que tal definição necessitaria estar mais evidente no texto.

Muito foi feito em relação ao estudo dos sítios arqueológicos na transição do período Helenístico para o período romano na região e um número cada vez mais elevado de publi- 
caçóes pode ser consultado pelos estudiosos que se dedicam a este amplo e importante tópico de pesquisa. Bem como todos os que pretendem aprofundar seus conhecimentos no tema. Dessa forma, o livro de Ovadiah e Ternheim fornece uma abordagem holística singular sobre o tema que habilita os estudiosos a traçar seus próprios caminhos de pesquisa. No entanto, entre os importantes sítios não contemplados neste livro, merece menção Sepphoris-Zippori, escavado por Zeev Weiss da Universidade Hebraica de Jerusalém, e a publicação do templo romano From Roman temple to Byzantine church: a preliminar report on Sepphoris in transition.

$\mathrm{Na}$ segunda parte do livro, treze lugares são abordados de maneira concisa. Embora breves, todas as descriçôes são baseadas em evidências históricas, epigráficas e numismáticas, com suas respectivas correspondências nos vestígios das edificaçóes, quando presentes. O livro termina com um epílogo. A importância desta breve conclusão, de apenas seis páginas, reside principalmente na análise dos diferentes tipos de fontes empregadas pelos autores na pesquisa. São listados os nomes das dezoito divindades às quais os santuários e templos foram dedicados em Israel e a bibliografia é acompanhada na sequência pela organização de pranchas com ilustraçôes dos sítios arqueológicos abordados.

Ao final desta resenha é importante relembrar uma das observaçóes presente no prefácio do livro: os sítios da região passaram por profundas modificações materiais ao longo dos séculos. De fato, a deterioração dos templos e santuários pela erosão e outros agentes naturais (entre os quais terremotos que atingiram a regiáo), e a destruição causada por roubo e pilhagem na Antiguidade, bem como o surgimento e o crescimento do cristianismo, são fatores capitais de mudança. A paisagem da Palestina foi radicalmente transformada com a ascensão do cristianismo no Oriente, apropriando sítios, destruindo e reconstruindo templos e santuários, promovendo, assim, a ressacralização dos lugares. Alguns destes complexos religiosos foram deliberadamente "esquecidos" e/ou destruídos na Antiguidade Tardia (quinto e sexto séculos EC) por ordem das autoridades cristâs e imperadores bizantinos, ou convertidos em igrejas e monastérios. $\mathrm{Ou}$ tros tantos foram demolidos pelas geraçóes posteriores, ou passaram por distintos processos pós-deposicionais (desastres naturais, incêndios, conquistas etc.). Como afirmou Lucrecio, uma faísca aqui e outra ali provoca um incêndio generalizado.

O número residual de templos romanos sobreviventes em Israel é muito pequeno se comparado à evidência e à preservação dos templos no Líbano, Jordânia e na Síria. A razão para esta discrepância parece ser evidente: as montanhas pouco povoadas e de difícil acesso do Líbano, o tamanho e a distância destas áreas na Síria e Jordânia, além da perda do controle da regiáo durante a Idade Média. No entanto, as fontes literárias, as analogias arqueológico-arquitetônicas e as evidências circunstanciais, fornecem informações suficientes para a compreensão dos contextos e das transformaçóes ocorridas na Antiguidade nessa regiâo. As percepções culturais evidenciadas nestes lugares sagrados e 
os complexos religiosos do período romano em Israel demonstram como o imperialismo romano atuou eficazmente através da religião e como a veneração e adoração de muitas e variadas divindades dos panteôes orientais e greco-romanos foram combinadas e consubstanciadas, fomentando a multiplicidade ritual do período. Além disso, é permitido supor que estes sítios arqueológicos, templos e santuários, demonstram não somente a realidade arquitetônica, mas também a atmosfera religiosa-cultual do período.

Entretanto, não é possível encerrar essa resenha a respeito dos templos romanos em Israel sem a profunda lástima sobre a destruição dos templos de Baal-Shamin (convertido em igreja no quinto século $\mathrm{EC}$ ) e Baal (Bel) em Palmyra. Assim como sobre o descalabro que foi acometido o arqueólogo sírio Khaled al-Asaad da Universidade de Damasco, brutalmente assasinado pelo extremismo monoteísta islâmico do grupo autodenominado Estado Islâmico do Iraque e do Levante (EIIL) ou Estado Islâmico do Iraque e da Síria (EIIS). O mundo contemporâneo testemunha mais uma onda de destruição de sítios arqueológicos, considerados Patrimônio da Humanidade, e a supressão intencional da memória coletiva. E assim, assistimos mais uma versão escabrosa de extremismo monoteísta e fundamentalismo religioso, que insiste em não saber conviver com a multiplicidade ritual presente em todas as sociedades do globo. Quando o objetivo de um grupo social atenta contra a vida e a memória dos povos, é nesse momento que se tornam mais significativas as palavras de Peter Burke: a funçáo do Historiador (e essencialmente do Arqueólogo) é lembrar a sociedade daquilo que ela quer esquecer. 